\title{
MUDANÇA DE HÁBITOS E ATITUDES PARA ALCANÇAR A ESTABILIDADE FINANCEIRA PESSOAL E CONHECER MELHOR A QUESTÃO AMBIENTAL PODEM INICIAR NA SALA DE AULA
}

\author{
Agda Nunes dos Santos Oliveira ${ }^{1}$ \\ Elaine Maria Luiza ${ }^{2}$
}

\section{Introdução a finanças pessoais}

Foram colocados vários cofrinhos plásticos em formato de porquinho em cima da mesa: vermelhos, verdes, amarelos, azuis, dourados, rosas, prateados. Os alunos foram convidados a escolher cada um o seu porquinho. Houve um breve tumulto devido às cores, as meninas queriam os rosas, e os corintianos não queriam os verdes, outros queriam o dourado, mas a quantidade de cofrinhos estava limitada a quantidade de alunos e as cores eram as que estavam ali em cima da mesa; não havia outros para trocar. Precisaram fazer um acordo entre eles, até que todos ficassem satisfeitos ou conformados com os porquinhos recebidos.

Após receberem um cofrinho, foram convidados a registrar, em forma de relatório, os valores que colocariam nele como: proveniente de economias ou de abstinência de gastos que consideravam supérfluos, ou novos hábitos de consumo. $\mathrm{O}$ professor faria o registro em seu portfólio docente, buscando dar transparência às atividades realizadas e às produções dos alunos. O problema a ser solucionado era: como falar em economizar e fazer, se a situação financeira não está possibilitando essas atitudes?

Ouve-se nos noticiários, lê-se em revistas econômicas, jornais e até na sala de aula, que é preciso "apertar os cintos", evitar gastos de qualquer natureza. Infelizmente, uma parte da população está vivendo da ajuda governamental. No mês de maio de 2015, o programa Bolsa Família cobria 13,7 milhões de famílias com um valor médio do benefício de $\mathrm{R} \$$ 167,95 (cento e sessenta e sete reais e noventa e cinco centavos). Esse dado demonstra que uma parte substancial da população está vivendo com ajuda de transferências diretas de renda do Governo Federal, auxílios como Bolsa Família, Seguro Desemprego etc., que colaboram na mitigação da pobreza gerando um efeito multiplicador, refletindo o cenário macroeconômico

Entretanto, conforme Paulo Freire, na Pedagogia da Autonomia (1996), a ajuda assistencialista torna a população "escrava" ou mesmo manipulável. As pessoas, quando têm a independência financeira, estão libertas e terão a possibilidade de fazer suas escolhas e tomadas de decisões livremente.

Evitar o crédito é um bom começo, especialmente quando o custo do dinheiro está alto. A taxa de juros no cartão de crédito, no mês de abril de 2016, estava por volta de $435,60 \%$ ao ano, levantamento na ANEFAC (Associação Nacional dos Executivos de Finanças, Administração e Contabilidade).

O grau de dificuldade para se liquidar uma dívida, se não houver pagamento da fatura do cartão de crédito na data de vencimento, mesmo que seja somente o valor mínimo autorizado pela operadora do cartão de crédito, é grande, sem comprometer as despesas básicas e essenciais. O cidadão pode ter o nome inserido na Lista de SPC (Sistema de Proteção ao Crédito) e perder sua liberdade de consumo.

Assim, uma futura proposta à Educação Financeira pessoal e familiar pode ser a solução de muitos problemas de várias áreas. Pode-se pensar inclusive na questão ambiental, porque,

\footnotetext{
${ }^{1}$ E-mail: agda.oliveira4@etec.sp.gov.br.

${ }^{2}$ E-mail: emalu@hotmail.com.
} 
dentro dessa perspectiva, minimiza-se o uso dos nossos recursos naturais renováveis e não renováveis, e diminui-se a emissão não só dos gases do efeito estufa, mas também dos materiais particulados que influenciam negativamente na saúde da população, das plantas e da própria cadeia alimentar. Essas emissões afetam diretamente os seres produtores que estão na base desta cadeia, além de poluir com alta demanda de efluentes os nossos mananciais.

\section{Desenvolvimento}

Após a entrega dos porquinhos, houve o relato do projeto: no primeiro dia, em que trabalhamos o assunto Finanças pessoais, fiz uma breve explanação e solicitei a opinião dos alunos, que totalizavam trinta e sete. Entreguei um texto com os assuntos: orçamento pessoal, orçamento familiar, os tipos de despesas fixas e variáveis.

A explanação tratou da importância de se fazer o orçamento pessoal e foi proposta aos alunos uma pesquisa do real valor das entradas mensais do capital e registro de todas as despesas ocorridas durante o mês, para posteriormente mensurar seu resultado. Nesse orçamento familiar, foram colocadas em planilha as despesas e as receitas dos envolvidos, para haver transparência da real situação financeira da entrada do dinheiro e as retiradas. Com os dados registrados, inicia-se a nova etapa, sobre os Tipos de Despesas, as essenciais e urgentes e as não tão necessárias e não urgentes. Foi nesse determinado momento que a sala de aula ficou pequena e a acústica ficou alterada. Os alunos queriam falar, outros falavam entre eles ou em pares, outros comigo e resmungavam. Pedi para terem calma; ouviria todos. Foi muito barulho. Em certo momento, pensei: deveriam se acalmar, estão confusos. Quando um aluno levantou a mão e perguntou: "Professora, estou desempregado há um ano, como vou registrar meus ganhos? Nunca dá para pagar as contas e não recebi o Fundo de Garantia, a empresa deu calote..."; outro aluno também levantou a mão e falou: "Minha esposa fica muito brava quando pergunto em que gastou o dinheiro, o que faço?". Mal terminou de falar, outra aluna replicou: "Não dá para ficar sem ir ao cabeleireiro e sem fazer as unhas, meu marido sempre reclama dos meus gastos, mas quer me ver bonita!”.

Sugeri que fizessem uma pergunta de cada vez, para que todos pudessem falar e também fossem ouvidos. Fui registrando de forma bem simples as questões colocadas e, para minha surpresa, os alunos, às vezes, pediam licença para dar alguma sugestão aos colegas.

O intervalo foi realizado e, quando voltamos, retomamos o assunto, a aula estava bastante interessante, tanto para mim, que pude conhecer melhor a realidade financeira dos alunos, que não se intimidaram em falar sobre as dificuldades financeiras e pedir ajuda para solucionar os problemas, como para os alunos, que estavam com uma reserva econômica e não sabiam a melhor forma de investir. Alguns pediram para falar em particular, sobre as dívidas e como solucionar o problema de forma mais adequada, sem sacrificar tanto a família.

Foi um dia de aula muito intenso, e algumas formas de se evitarem gastos foram sugeridas aos alunos, principalmente, aos que já estavam com saldo negativo, dívidas com cartão de crédito, nome inserido no SPC. Como solucionar?

Foram entregues mais artigos para avaliar situações e tomadas de decisão sobre as finanças pessoais. Cada aluno pôde registrar situações e buscar soluções para suas dívidas. A grande maioria, no início, propôs o diálogo em família, formas de diminuir despesas fixas e, quando necessário, alterar rotinas para diminuir as despesas variáveis.

$\mathrm{O}$ caos aparente que tivemos na primeira aula foi muito produtivo e possibilitou que fizessem a análise crítica das finanças pessoais e também harmonizar a sala de aula. 


\section{Resultado da intervenção}

As intervenções que foram realizadas com os alunos no decorrer do $1^{\circ}$ semestre de 2016 , por meio da entrega de cofrinhos e relatórios sobre finanças, sobre as formas de economizar, de colocar as dívidas em dia. Os alunos foram convidados a fazer relatórios sobre o entendimento do texto lido e debatido em sala de aula. No final do semestre, os alunos abriram o cofrinho para quantificarem as economias guardadas e escreverem o relatório final da experiência em guardar e significado do projeto para cada um deles.

A conclusão foi que muitos haviam perdido o hábito de economizar e não tinham ideia dos gastos não ponderados e das compras sem responsabilidade. Uma quantidade pequena de alunos tinha o hábito de economizar e fazer reservas do salário mensal.

O projeto proporcionou aos alunos um olhar mais disciplinado e responsável para cuidar das dívidas atrasadas e procurar formas de saldar sem pagar juros altos, negociações mais cuidadosas para cumprir até o final do prazo estipulado em contrato. Os relatórios entregues pelos alunos demonstraram a preocupação em ter hábitos de consumo mais responsáveis e que um dos motivos do não pouparem foi a pressa em ter bens de consumo duráveis e não ficarem desatualizados em seus aparelhos eletrônicos, como celular, smartphones, notebooks, computadores, tablets, em geral.

\section{Percepção ambiental do descarte inadequado de lixo}

A Educação financeira pessoal e familiar pode ser a solução de muitos problemas, inclusive na questão ambiental, pois, dentro desta perspectiva, conscientizar os alunos sobre o consumo desenfreado e, consequentemente, dar um destino correto para os resíduos diminui a poluição ambiental, tanto na atmosfera, quanto na hidrosfera e litosfera, pois o ser humano não consegue ter seus dejetos inteiramente reciclados.

A problemática da geração de resíduos é universal, pois todos os países produzem toneladas diárias de lixo, o que justifica buscarmos mecanismos para minimizar e conscientizar as pessoas sobre essa questão.

Há uma enorme variedade de lixo, dentro dela, destacam-se os resíduos orgânicos e inorgânicos, tais como: vidro, metal, plástico e papel e estes se enquadram nos recicláveis. Dentro dessa percepção ambiental, os alunos devem vivenciar essa ideia, com a prática do consumo consciente, fazer economia dos bens desnecessários e separar os resíduos de maneira correta, para, posteriormente, gerar renda para si e, consequentemente, minimizar a degradação ambiental. Segundo dados do IBGE (2002), a geração per capita de resíduos no Brasil está entre 450 e 700 gramas por habitante, nos municípios com população menor a 200 mil habitantes, e entre 700 e 1200 gramas, em municípios com população acima de 200 mil habitantes.

A geração de lixo está crescendo a despeito dos números que se projetam. Em relação ao saneamento, o Brasil apresenta índices de país subdesenvolvido; o que apenas reflete a demora nas ações públicas no setor, bem como a deseducação e o desinteresse da população pelo cuidado com o meio ambiente. Os bons hábitos de consumo devem ser priorizados pelos cidadãos.

\section{Referências}

BANCO CENTRAL DO BRASIL. O Programa de Educação Financeira do Banco Central. Disponível em: 〈http://www.bcb.gov.br/ ?BCEDFIN>. 
DOMINGOS, R. Como Controlar o Seu Orçamento. São Paulo: DSOP Educação Financeira, 2012.

DOMINGOS, R. Como empreender com equilíbrio financeiro. São Paulo: DSOP Educação Financeira, 2012.

DOMINGOS, R. Como reduzir o impulso de comprar. São Paulo: DSOP Educação Financeira, 2012.

GARCIA, R. L. Do baú da memória: história de professora. In: ALVES, Nilda; GARCIA, Regina Leite (Org.). O sentido da escola. Rio de Janeiro: DP\&A, 2000.

IBGE - INSTITUTO BRASILEIRO DE GEOGRAFIA E ESTATÍSTICA. Pesquisa Nacional de Saneamento Básico, 2000. Rio de Janeiro: Departamento de População e Indicadores Sociais, 2002.

MONTEIRO et al. Manual de Gerenciamento Integrado de Resíduos Sólidos. Secretaria Especial de Desenvolvimento Urbano da Presidência da República (Sedu), Rio de Janeiro.

MEU BOLSO FELIZ. Despesas e Orçamento. Disponível em: <http://meubolsofeliz.com.br/estouno-sufoco/minhas-dividas/receitas-despesas-e-orcamento>. Acesso em: 16 out. 2016.

FREIRE, P. Pedagogia da autonomia: saberes necessários à pratica educativa. Coleção Leitura, Rio de Janeiro: Paz e Terra, 1996.

Plano CDE. $1^{o}$ Mapeamento Nacional das Iniciativas de Educação Financeira. ENEF (Estratégia Nacional de Educação Financeira), 2013.

Plano CDE. Mapa da Educação Financeira no Brasil. ENEF (Estratégia Nacional de Educação Financeira), 2013. 